\title{
Thermodynamic Modeling of Ethanol Fumigation in a Diesel Engine
}

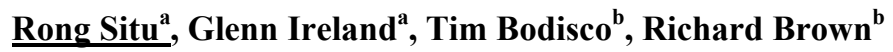 \\ ${ }^{a}$ School of Engineering and Physical Sciences, James Cook University, Townsville, QLD 4811, Australia. \\ ${ }^{b}$ Faculty of Science and Engineering, Queensland University of Technology, Brisbane, QLD 4001, Australia \\ Email: rong.situ@jcu.edu.au
}

\begin{abstract}
Due to rapidly diminishing international supplies of fossil fuels, such as petroleum and diesel, the cost of fuel is constantly increasing, leading to higher costs of living, as a result of the significant reliance of many industries on motor vehicles. Many technologies have been developed to replace part or all of a fossil fuel with bio-fuels. One of the dual fuel technologies is fumigation of ethanol in diesel engines, which injects ethanol into the intake air stream of the engine. The advantage of this is that it avoids any costly modification of the engine high pressure diesel injection system, while reducing the volume of diesel required and potentially increasing the power output and efficiency.

This paper investigates the performance of a diesel engine, converted to implement ethanol fumigation. The project will use both existing experimental data, along with generating computer modeled results using the program AVL Boost. The data from both experiments and the numerical simulation indicate desirable results for the peak pressure and the indicated mean effective pressure (IMEP).

Increase in ethanol substitution resulted in elevated combustion pressure and an increase in the IMEP, while the variation of ethanol injection location resulted in negligible change. These increases in cylinder pressure led to a higher work output and total efficiency in the engine as the ethanol substitution was increased. In comparing the numerical and experimental results, the simulation showed a slight elevation, due to the inaccuracies in the heat release models. Future work is required to improve the combustion model and investigate the effect of the variation of the location of ethanol injection.
\end{abstract}

Keywords: Compression-Ignition Engine, Fumigation, Ethanol, Bio-fuel, Thermodynamic modeling 


\section{INTRODUCTION}

In recent years, it has become increasingly clear that international fossil fuel supplies are limited and will not last indefinitely, with worldwide shortages leading to significant increases in fuel costs. Due to the prevalent use of fossil fuels in combustion engines across nearly all industries, these price increases can and have led to a higher cost of living across the board. Because of the economic significance of the cost of fuel, efforts are being made to determine a renewable fuel source in order to end the shortage. At this point in time, the most viable replacement fuel source is alcohol based fuels, as they can be used in combustion type engines with minimal modification required. Of the alcohol fuel types, ethanol is the most practical replacement, as it is non-toxic and can be readily made from many plant crops, including sugar cane, sorgum, corn and hemp.

In order to take advantage of alcohol fuels in existing engines, with relatively little modification or retuning, methods of dual fuel delivery have been developed, in order to deliver the alcohol, along with either diesel or petrol to the cylinder. One method of this delivery is fumigation of ethanol in diesel engines, which injects ethanol into the intake air stream of the engine. The advantage of this is that it avoids any costly modification of the engine's high pressure diesel injection system, while reducing the volume of diesel required and potentially increasing the power output and efficiency.

This paper aims to test and evaluate the performance of an ethanol fumigated diesel engine; this will be achieved through both experimental testing of a physical engine, along with computational testing using a one dimensional, thermodynamic program, AVL Boost.

\section{LITERATURE REVIEW}

Renewable energy has quickly become one of the key topics of discussion during the last decade, with substantial research and development dedicated to the search for alternate means of powering our society, the reasoning for this is that fossil fuels are being rapidly depleted, especially easily accessed reserves of oil and gas (Moriarty and Honnery, 2011). Along with this, these alternative fuels have a potential to improve air quality and mitigate global warming (Demirbas, 2009).

There are a number of renewable energy solutions, both in use and in development, that have been covered in the recent literature, this review however, will focus on the alternative fuels, and more specifically, alcohols. While alcohol based fuels have been present in the market since as early as the late 1800 s, it is only recently that research has brought society to the point where alcohol based fuels can be used for transportation applications (Minteer, 2006). While in the past, alcohol based fuels have had periods of short-term success in the market, during periods of crude oil shortages, the world is moving towards a sustainable energy era, with a major emphasis on energy efficiency and renewable energy sources and bio-origin fuels coming from biological raw material sources have proven to be a good substitute for oil in small energy needs. In relation to this paper, the diesel engine is widely used in heavy trucks, locomotives and other forms of transport equipment, playing a large role in an energy economy, and therefore, may also contribute significantly to pollution. There are a number of potential alternative fuels for use in diesel engines, such as biodiesel, biogas and alcohols (most commonly methanol and ethanol in automotive applications) (Chauhan, et al. 2011). This is because methanol and ethanol are the most commercially viable alcohols (Minteer, 2006), and at present, unit cost usually determines which energy source to use (Moriarty and Honnery, 2011).

Ethanol has been considered an important alternative fuel for engines for a long period of time, as it solves a number of problems facing traditional crude based fuels, such as emission of greenhouse gases and particulates (Nguyen and Honnery, 2008; Surawski et al. 2010, 2013). This is largely due to the ability to produce the fuel using biomass products from agricultural industries, such as sugar cane and corn farming (Minteer, 2006), which will help to boost the agricultural industry. In comparison to methanol, ethanol has a lower enthalpy of vaporisation and auto-ignition temperature, leading to better ignition characteristics (Yilmaz, 2012). Ethanol is the most popular alcoholic fuel, because it is created from renewable agricultural products and also, it is less toxic, due to both the fuel itself and the potential by-products of incomplete combustion having lower toxicities in comparison to other alcoholic fuels.

While there are a number of significant advantages to using alcoholic fuels, a number of limitations must be overcome, for example, in comparison to crude based fuels, alcohols offer low lubricity, difficulty of vaporization and high auto-ignition temperatures (Yilmaz, 2012). Due to the high auto-ignition temperature, igniting alcohols in a compression engine requires a higher compression ratio, use of glow plugs or a catalyst (Nguyen and Honnery, 2008). However, many of these issues can be overcome in diesel engines by mixing the alcohol with the diesel fuel, which allows the ignition of the diesel fuel to ignite the alcohol and can lead to advantages such as reduction of NOx and particulate matter in exhaust gases (Yilmaz and Sanchaz, 2011), 
Zhang et al. 2011). This paper looks to analyze the performance of a diesel engine with a specific form of dual fuel delivery, fumigation. Fumigation involves the carburetion of the secondary fuel (the alcohol) into the intake air stream of the diesel engine (Chauhan, et al. 2011). An advantage of fumigation over mixing is that it is possible to alter the amount of alcohol injected to match the actual requirement; also, because the alcohol is not premixed, an emulsifier is not necessary to ensure proper mixing (Zhang et al. 2011).

Ethanol is generally the favored alcohol in dual fuel blends and fumigation, receiving the focus of most literature on the topic; this is likely due to ethanol's existing presence in the automotive industry both as a stand-alone fuel in some racing disciplines and as a fuel additive to petrol (Minteer, 2006). When used as an additive, ethanol has been shown to reduce harmful exhaust emissions in both bio-diesel and diesel, however ethanol has a heating value of approximately $60 \%$ of diesel's, meaning high substitutions could have the potential to alter combustion timing and energy (Nguyen and Honnery, 2008). The reductions in exhaust toxins achieved through running an ethanol-diesel fumigation system are quite substantial, with $20 \%$ to $30 \%$ decreases in carbon monoxide emissions and $20 \%$ to $40 \%$ decreases in particulate matter (Minteer, 2006).

In testing the outputs of an engine, there were two main paths that can be followed, physically obtaining and modifying an engine in order to obtain experimental results, or utilizing a computer simulation program to analyze the performance. The main advantage of computer simulation in engine testing, is that it can offer a low-cost analysis of the influence of alternative fuels on injection characteristics and consequently of exhaust emissions (Torres-Jimenez et al., 2012). This paper both conducts physical experiments and numerical simulation. The software to be used is AVL Boost, a one dimensional engine simulation program. Using Boost, it is possible to adjust every parameter of the model freely, without being forced to physically alter the engine. This means it is possible to more accurately control engine parameters in order to achieve more accurate and directly comparable results.

\section{METHODOLOGY}

There are a number of different methods that can be used in computationally testing engine performance, the method chosen to be utilized in this paper is a one-dimensional thermodynamic model using the program AVL Boost (Lesnik et al. 2013). This program takes inputs of engine specifications and geometries, along with fuel mixtures and other inputs, in order to accurately conduct a 1D thermodynamic model which is based on conservation of energy (Frist Law) to analyze the behavior of the engine. The main tool used in AVL Boost is the workspace, seen with the engine model to be used in this project in Figure 1. The engine model is built within the workspace, using parts selected from the element tree at the left of the window. Using these elements, the model is adjusted to match the physical parameters of the diesel engine.

The AVL Boost models used in this paper were developed on a 6 cylinder Cummins ISBe 220-31 turbocharged and aftercooled diesel engine. The bore dimension is $102 \mathrm{~mm}$, the stroke length is $120 \mathrm{~mm}$, and the volume is 5.9 liters. The compression ratio is 17.3:1.

\subsection{Secondary ethanol fuel injection}

There are a number of decisions to be made regarding the method of fuel injection. First and foremost, the placement of the injector along the air intake assembly must be determined. In this paper, the effect of fumigation will be analyzed with the injector placed in a number of different positions in relation to components of the intake system. The three positions to be tested are (1) before the turbocharger, (2) between the turbocharger and intercooler and (3) after the intercooler, as show in Figure 1. The turbocharger and intercooler can be seen at $\mathrm{TC} 1$ and $\mathrm{CO} 1$ respectively in Figure 1.

Another consideration for the method of fuel injection, which applies to the injection of ethanol, is determining whether to inject the fuel as a liquid or a vapor. In the case of injecting before the turbo or after the intercooler, it is desirable for the fuel to be injected as a vapor, as liquid fuel passing through the turbo or entering the combustion chamber has the potential to cause damage to components. When injecting between the turbo and the intercooler however, liquid fuel injection is not likely to cause this problem. A potential advantage of injecting as a liquid is that as the fuel vaporizes, it will draw heat from the air, cooling it and in doing so, possibly improve the engine's performance. In order to determine the effect of liquid injection in comparison to vapor, the ethanol test of the injector between the turbo and intercooler will be completed using both liquid and vapor injection. 


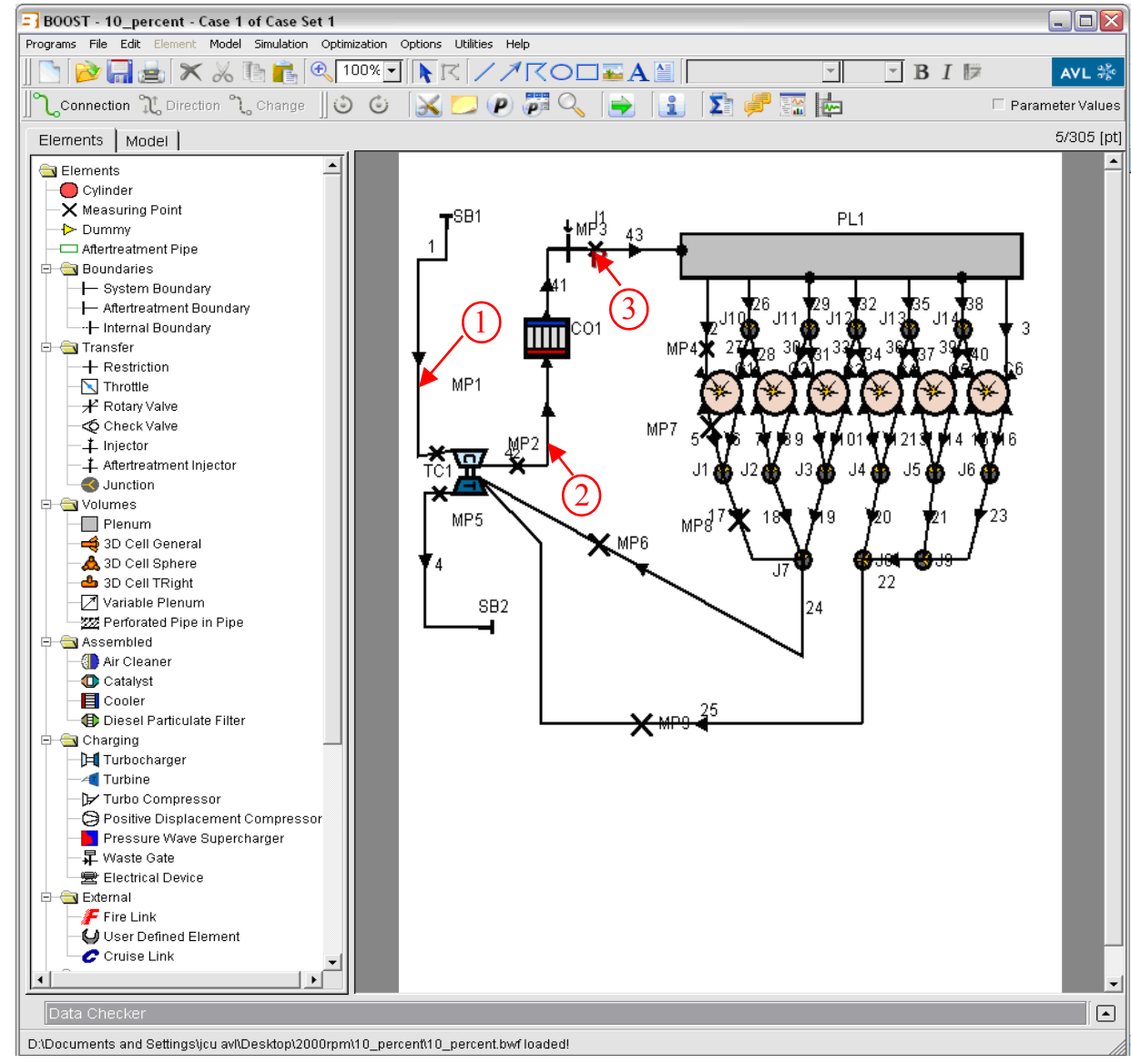

Figure 1. AVL Boost model.

\subsection{Combustion model}

The combustion model used in this thesis is the double vibe function (Lesnik et al. 2013), this function characterizes the heat release of the engine and is defined by the start of combustion and the duration two separate pulses of combustion, which are each defined by the parameter ' $a$ ' and the shape parameter ' $m$ '. The double vibe function is a combination of two single vibe functions; the purpose of this is to more accurately model the combustion of both the pre-mixed fuel and the fuel that diffuses during combustion. This single vibe function has the following form:

$$
\frac{d x}{d \alpha}=\frac{a}{\Delta \alpha_{c}}(m+1) y^{m} e^{-a y^{(m-1)}}
$$

where $d x=\frac{d Q}{Q}, y=\frac{\alpha-\alpha_{0}}{\Delta \alpha_{c}}, Q$ is the fuel heat input, $\alpha$ is the crank angle, $\alpha_{0}$ is the angle of the start of combustion, $\Delta \alpha_{\mathrm{c}}$ is the angle of combustion duration, $m$ is the shape parameter, and $a$ is the Vibe parameter. For complete combustion, the parameter $a$ must be set to 6.9. In order to utilize a double vibe function, the parameter $\Delta \alpha_{\mathrm{c}}$ and $m$ are specified for each single vibe function of the pair, as well as the fuel allotment, which designates the fraction of the fuel to be combusted by Vibe 1 function.

\section{RESULTS AND DISCUSSIONS}

\subsection{Experimental data}

Ethanol fumigation experiments were performed with a 6-cylinder 4-stroke Cummins ISBe 220-31 engine at the Biofuel Engine Research Facility (BERF) of Queensland University of Technology (QUT). A total of two engine speeds (1500rpm and 2000rpm, respectively) and 5 ethanol mixing ratios per speed were conducted. The ethanol was injected as a vapor in to the air intake at the inlet manifold between the turbocharger and the 
intercooler (Bodisco and Brown, 2013). The energy percentage of ethanol, mass flow rates of diesel and ethanol, add energy percentage (from pure diesel condition), Brake Median Effective Pressure (BMEP) and thermal efficiency are summarized in table 1.

Table 1 Test conditions

\begin{tabular}{|c|c|c|c|c|c|c|c|c|c|c|c|c|c|c|}
\hline \multirow{3}{*}{ 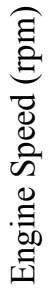 } & \multirow{3}{*}{ 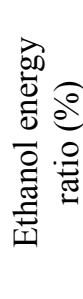 } & \multirow{3}{*}{ 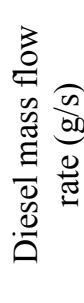 } & \multirow{3}{*}{ 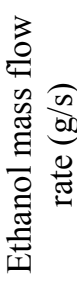 } & \multirow{3}{*}{ 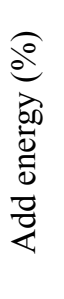 } & \multirow{3}{*}{$\begin{array}{l}\sum_{\infty}^{\infty} \\
\sum_{\infty}^{\infty} \\
\infty\end{array}$} & \multirow{3}{*}{ 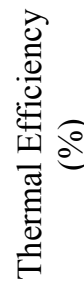 } & \multicolumn{4}{|c|}{$\begin{array}{l}\text { Peak Pressure } \\
\qquad(\mathrm{MPa})\end{array}$} & \multicolumn{4}{|c|}{$\begin{array}{l}\text { IMEP } \\
(\mathrm{kPa})\end{array}$} \\
\hline & & & & & & & \multirow[t]{2}{*}{$\operatorname{Exp}$} & \multicolumn{3}{|c|}{$\begin{array}{l}\text { Numerical } \\
\text { Simulation }\end{array}$} & \multirow[t]{2}{*}{ Exp } & \multicolumn{3}{|c|}{$\begin{array}{l}\text { Numerical } \\
\text { Simulation }\end{array}$} \\
\hline & & & & & & & & 1 & 2 & 3 & & 1 & 2 & 3 \\
\hline \multirow{5}{*}{$\stackrel{8}{\circ}$} & 0 & 8.36 & 0 & -- & 17.9 & 35.8 & 10.7 & 14.4 & 14.4 & 14.4 & 1076 & 1596 & 1596 & 1596 \\
\hline & 3.65 & 7.56 & 0.45 & 5.94 & 17.4 & 38.4 & 11.1 & 14.6 & 14.6 & 14.6 & 1110 & 1660 & 1660 & 1660 \\
\hline & 14.6 & 6.69 & 1.82 & 5.33 & 19.7 & 38.5 & 12.0 & 15.7 & 15.7 & 15.7 & 1208 & 1849 & 1850 & 1851 \\
\hline & 27.6 & 5.80 & 3.51 & 3.06 & 21.9 & 37.9 & 13.4 & 17.1 & 17.1 & 17.2 & 1352 & 2083 & 2074 & 2085 \\
\hline & 36.2 & 4.99 & 4.49 & 4.15 & 24.1 & 37.1 & 15.9 & 18.1 & 18.1 & 18.3 & 1569 & 2202 & 2202 & 2217 \\
\hline \multirow{5}{*}{ ஓ્ণ } & 0 & 9.46 & 0 & - & 14.5 & 39.0 & 12.5 & 13.7 & 13.7 & 13.7 & 1257 & 1502 & 1502 & 1502 \\
\hline & 7.88 & 8.46 & 1.15 & 2.44 & 15.3 & 40.2 & 1.8 & 14.6 & 14.6 & 14.6 & 1270 & 1672 & 1672 & 1672 \\
\hline & 20.0 & 7.47 & 5.96 & 1.12 & 17.0 & 39.4 & 13.4 & 16.0 & 16.1 & 16.1 & 1312 & 1927 & 1927 & 1933 \\
\hline & 28.7 & 6.69 & 4.27 & 0.61 & 18.7 & 39.4 & 14.8 & 17.3 & 17.4 & 17.4 & 1483 & 2108 & 2119 & 2117 \\
\hline & 33.9 & 5.85 & 4.76 & 4.27 & 20.3 & 41.7 & 16 & 17.9 & 18.0 & 18.0 & 1612 & 2176 & 2189 & 2186 \\
\hline
\end{tabular}

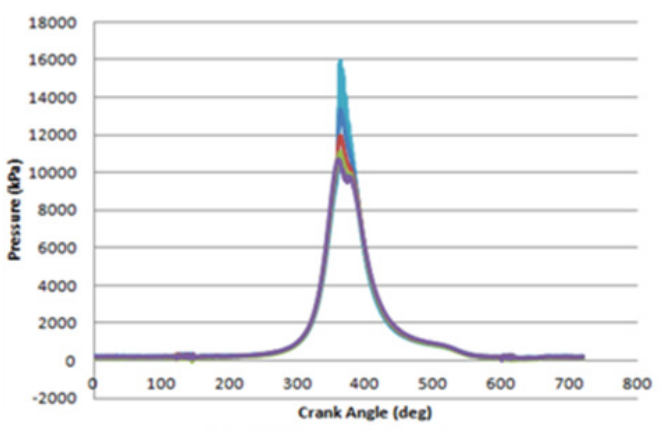

(a) $1500 \mathrm{rpm}$, full load

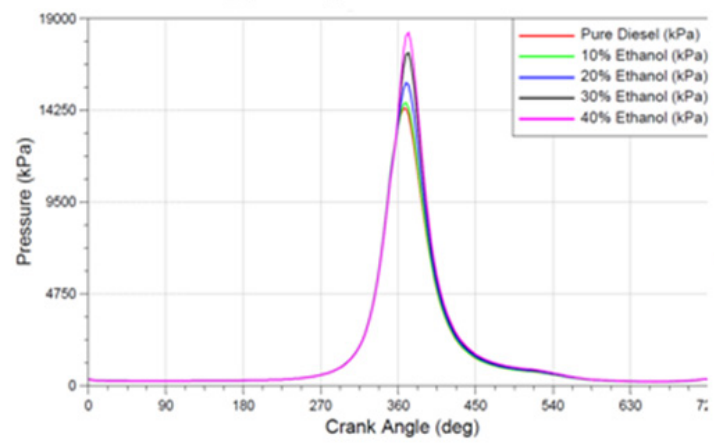

(c) $1500 \mathrm{rpm}$, full load, after Intercooler

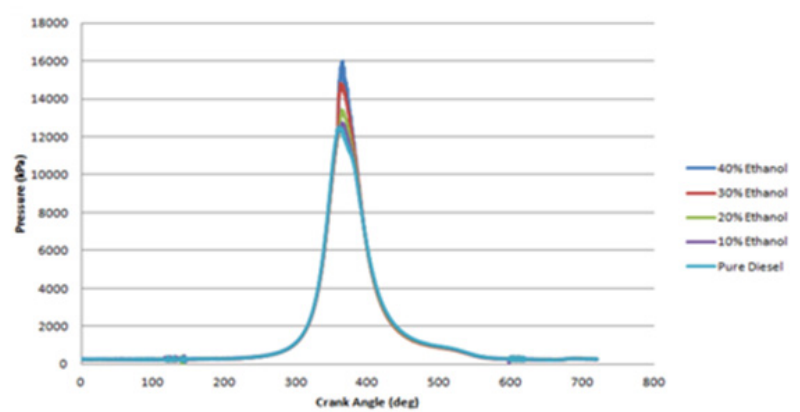

(b) $2000 \mathrm{rpm}$, full load

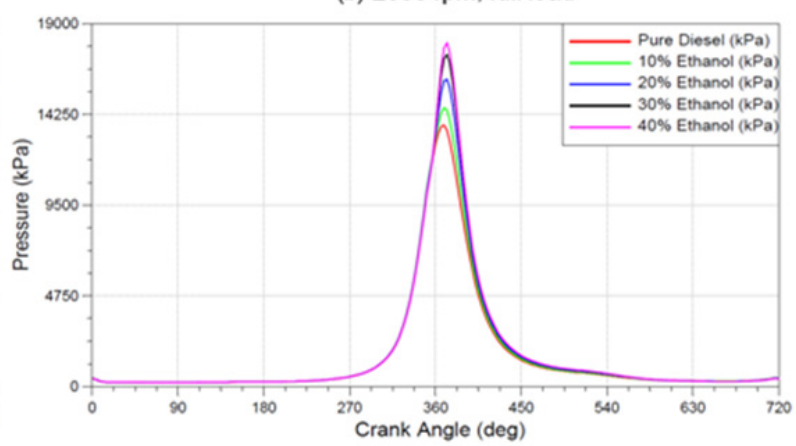

(d) $2000 \mathrm{rpm}$, full load, after Intercooler

Figure 2. Pressure vs crank angle for, full load conditions with ethanol injection after intercooler: (a), (b) experimental results; (c), (d) simulation results.

The in-cylinder pressure was measured in Cylinder 1 with a $\mathrm{PCB} 112 \mathrm{~B} 1$ piezoelectric transducer at a sample rate of 200,000 Hz (Bodisco et al 2012). The pressure vs. crank angle diagrams are plotted in Figure 2 (a) and 
(b). It is shown that the major output affected by the substitution of ethanol is the peak pressure reached during combustion. The major contributing factor to the significant increase in peak pressure during combustion is the difference in combustion propagation between the different case conditions. For pure diesel fuel, the combustion occurs as the diesel fuel is injected and mixes with the high pressure air within the cylinder. Therefore, in a pure diesel case, only a small portion of the fuel is premixed for initial auto ignition after which the rate of combustion is diffusion limited by the rate which the diesel can evaporate and mix with the air in the cylinder. Because of the time taken to sufficiently mix, the combustion is spread throughout a wider angle of the power stroke. The significance of this is that the cylinder volume increases as the crank rotates, meaning that a similar energy input will result in a lower overall peak pressure.

In the case of the ethanol fumigated runs, however, a portion of the diesel fuel has been replaced with an ethanol volume that maintains a constant overall heating value. The effect of this fumigation is that the ethanol portion is premixed with the air within the cylinder, prior to diesel injection and combustion. The result of this premixing is that upon diesel injection, the diesel initiates the combustion, which is then able to propagate throughout the cylinder very quickly, igniting the ethanol fuel, provided the minimum air/fuel ratio of ethanol is achieved. With this faster combustion, heat is released in the cylinder at a much higher rate, meaning the ratio of heat increase to volume increase is much higher than in the pure diesel case during the early stages of combustion, resulting in the increased peak pressure.

From the raw data provided by the experiments, it was possible to develop a number of results, which are indicative of the change in the engine's performance, due to the introduction of ethanol into the combustion. From the results given in Table 1Error! Reference source not found., the thermal efficiency, peak pressure, and the Indicated Median Effective Pressure (IMEP) can be observed. In calculating the thermal efficiency, the energy input is the total enthalpy of combustion of the fuels in cylinder, based on values of $H_{\text {diesel }}=42934$ $\mathrm{kJ} / \mathrm{kg}$ and $H_{\text {ethanol }}=26811 \mathrm{~kJ} / \mathrm{kg}$ (Borgnakke and Sonntag, 2008).

As stated earlier, the peak pressure reached during combustion increases with the addition of ethanol, so too does the IMEP of the cycle. IMEP can be a great indicator of engine performance, as it represents the average pressure throughout the work cycle of the cylinder and can therefore be used to estimate the work and/or power output of the cylinder and therefore the engine. In observing the 1500rpm case, it is observed that the IMEP increases exponentially with the increase in ethanol substitution, leading to a higher net work output (net work calculations are based on an individual cylinder displacement volume of $0.981 \mathrm{~L}$ ).

In analyzing the results of the $2000 \mathrm{rpm}$ run, it is apparent that the higher engine speed has lead to an increase in the pressure and work output of the cylinder's performance across all fuel substitutions, which is generally expected due to an increase in turbo pressure and cylinder temperature, among other factors. While the overall pressure has increased, the rate of increase due to ethanol substitution decreases at higher temperatures, which affects the peak pressure, IMEP and net work variations due to fuel constitution.

\subsection{Numerical simulation results}

The simulated results were compiled into Figure 2 (c) and (d), corresponding to the experimental results from the physical engine, in Figure 2 (a) and (b) in order to enable analysis and comparison between experimental and simulated results. The simulation results indicate an increase in peak pressure as the ethanol substitution is increased. One interesting difference however, is the decrease in pressures across the range of values between the $1500 \mathrm{rpm}$ and $2000 \mathrm{rpm}$ cases, whereas the experimental data indicated an increase in pressure. The likely reason behind this is the definition of the fuel efficiency of the engine as a function of a mass flow per unit of time, meaning that at higher engine speeds there is less fuel per cycle.

The pressure vs. crank angle diagrams of the simulated results, once again confirmed the pressure trends confirmed in the $P-V$ diagram. Along with this, a slight difference in the crank angle of the peak pressure can be observed, with a combustion delay due to the presence of ethanol. This finding is in line with the experimental data analyzed earlier in that there is an increased delay in both sets of results.

Based on the graphed results in Figure 2 and a number of other outputs, a series of tabulated data has been compiled for each engine speed and injector location in Table 1 for peak pressure and IMEP. In analyzing the computational output data, it is clear that the trends of each case roughly follow those displayed in the experimental data, with peak pressures and IMEP values gradually increasing with increases in ethanol substitution, regardless of injector location. While the trends may be similar between in that all data sets show pressure increases, it is noted that the magnitudes of the pressures and increases in pressure are significantly inflated in the computational results, with the mean $1500 \mathrm{rpm}$, computational peak pressure result for pure diesel case sitting at approximately $148 \%$ of the experimental value, and the equivalent 2000 
rpm result at $119 \%$ of its counterpart. It is hypothesized that the major cause for this is an elevated specification of the fuel economy for the computational model, as only limited data was available and did not account for varying engine speeds. Due to the elevated pressure results, the calculated IMEP was also high in comparison to experimental values, as were the values for the net work of the cycle across all injection points.

\section{CONCLUSIONS}

Based on the results of this project, indications are that ethanol fumigation can be successfully implemented in a direct injection diesel engine. The data from both the experimental testing and the AVL Boost model indicate desirable results for net work output and engine efficiency.

Despite these favorable results, there were a number of limitations noted in the accuracy of the Boost model when compared to the experimental data. These include elevated results for pressure to determine the peak pressures. While the model was effective in modeling trends in results similar to the actual effects of ethanol fumigation, the magnitudes of these effects were generally exaggerated. The cause of these inaccuracies is believed to be limitations in the calculation of fuel mass flow rate per cycle and the accuracy of the double vibe heat release functions as the combustion model.

In the case of determining the effect of altering ethanol injection locations in the model, the results were largely inconclusive. It was found that the changing of ethanol injection location has almost no effect on the engine performance. This suggests that AVL Boost is limited in its ability to calculate thermodynamic relations in some component types and more future work is required to explore the improvement of the model.

\section{REFERENCES}

Bodisco, T., Brown, R. (2013) Inter-cycle variability of in-cylinder pressreu parameters in an ethanol fumigated common rail diesel engine. Energy, 52, 55-65.

Bodisco, T., Reeves, R., Situ, R., Brown, R. (2012) Bayesian models for the determination of resonant frequencies in a DI diesel engine. Mechanical System and Signal Processing, 26, 305-314.

Borgnakke, C. and Sonntag, R. E. (2009). Fundamentals of Thermodynamics (7th ed), John Wiley \& sons.

Chauhan, B. S., Kumar, N., Pal, S. S., \& Du Jun, Y. (2011). Experimental studies on fumigation of ethanol in a small capacity Diesel engine. Energy, 36(2), 1030-1038.

Demirbas, A. (2009). Political, economic and environmental impacts of biofuels: A review. Applied Energy, 86, S108-S117.

Lesnik, L., Vajda, B., Zunic, Z., Skerget, L., Kegl, B., The influence of biodiesel fuel on injection characteristics, diesel engine performance, and emission formation. Applied Energy, 111, 558-570.

Minteer, S. (Ed.). (2006). Alcoholic Fuels (Vol. 112). Boca Raton, FL: CRC Press Taylor \& Francis Group.

Moriarty, P., \& Honnery, D. (2011). The transition to renewable energy: make haste slowly. Environmental Science and Technology, 45(7), 2527-2528.

Nguyen, D., \& Honnery, D. (2008). Combustion of bio-oil ethanol blends at elevated pressure. Fuel, 87(2), 232-243.

Surawski, N. C., Ristovski, Z. D., Brown, R. J., Situ, R. (2012) Gaseous and particle emissions from an ethanol fumigated compression ignition engine, Energy Conversion and Management, 54, 145-151.

Surawski, N. C., Mijevic, B., Roberts, B., Modini, R., Situ, R., Brown, R. J., Bottle, S. Ristovski, Z. D. (2010) Particle emission, volatility and toxicity from an ethanol fumigated compression ignition engine, Environmental Science and Technology, 44, 229-235.

Torres-Jimenez, E., Kegl, M., Dorado, R., \& Kegl, B. (2012). Numerical injection characteristics analysis of various renewable fuel blends. Fuel, 97, 832-842.

Yilmaz, N. (2012). Performance and emission characteristics of a diesel engine fuelled with biodieselethanol and biodiesel-methanol blends at elevated air temperatures. Fuel, 94, 440-443.

Yilmaz, N., \& Sanchez, T. M. (2012). Analysis of operating a diesel engine on biodiesel-ethanol and biodiesel-methanol blends. Energy, 46(1), 126-129

Zhang, Z. H., Tsang, K. S., Cheung, C. S., Chan, T. L., \& Yao, C. D. (2011). Effect of fumigation methanol and ethanol on the gaseous and particulate emissions of a direct-injection diesel engine. Atmospheric Environment, 45(11), 2001-2008. 